\title{
Effect of Starting Materials on the Morphological and Optical Properties of Er Doped $\mathrm{BaTiO}_{3}$ Nanocrystalline Films
}

\author{
M. García-Hernández ${ }^{1, *}$, A. García-Murillo², F. de J. Carrillo-Romo ${ }^{2}$, Á. de J. Morales-Ramírez ${ }^{2}$, \\ M. A. Meneses-Nava ${ }^{3}$, B. Gonzalez-Penguelly ${ }^{2}$ and V. Garibay Febles ${ }^{4}$ \\ ${ }^{1}$ Departamento de Ciencias Naturales, DCNI, Universidad Autónoma Metropolitana, Unidad Cuajimalpa, \\ Pedro Antonio de los Santos 84, C. P. 11850 México D. F., México \\ ${ }^{2}$ Instituto Politécnico Nacional-CIITEC Azcapotzalco, Cerrada de Cecati $S / N$, \\ Col. Santa Catarina, Del. Azcapotzalco; C. P. 02250 México D. F., México \\ ${ }^{3}$ Centro de Investigaciones en Óptica A. C, A. P. 1-94837150, León, Gto., México \\ ${ }^{4}$ Instituto Mexicano del Petróleo, Programa de Ingeniería Molecular, México D.F., México
}

\begin{abstract}
Erbium $(5 \% \mathrm{~mol})$ doped $\mathrm{BaTiO}_{3}$ films were prepared using different metallic precursors: barium acetate, titanium butoxide and isopropoxide with different molar ratios. Three different experimental methodologies (A, B and C) were proposed in order to obtain optical quality thick films incorporating polyvinylpyrrolidone (PVP) as a rheological agent at the sol stage. In all cases, $\mathrm{Er}$ doped $\mathrm{BaTiO}_{3}$ films were deposited in silica quartz substrates. The morphology was controlled by means of the incorporation of the chelating agent and water molar ratios. Through the three different synthesis routes, $\mathrm{Er}_{\mathrm{BaTiO}}$ films presented mainly the cubic phase, as observed by X-ray diffraction. The films presented a homogeneous and crack-free surface of cross-linked particles. Photoluminescent results show that the highest intensity emission of the $\mathrm{Er}^{3+}\left({ }^{4} \mathrm{~S}_{3 / 2} \rightarrow{ }^{4} \mathrm{I}_{15 / 2}\right)$ was obtained from Er:BaTiO 3 film prepared using $\mathrm{C}$ methodology, which could be associated with the film's thicknesses. [doi:10.2320/matertrans.M2012313]
\end{abstract}

(Received September 10, 2012; Accepted February 19, 2013; Published April 5, 2013)

Keywords: erbium, BaTiO 3 , films, sol-gel, polyvinylpyrrolidone (PVP)

\section{Introduction}

The evolution of nanotechnology has increased demands for portable computers, communication equipment and consumer electronic products in recent years. Nanotechnology has emerged as a technological alternative, which allows to fulfill special requirements as improve resolution and quality in devices that will soon become ubiquitous products in our homes, workplaces and elsewhere. ${ }^{1,2)}$ In particular, erbium-doped waveguides films have attracted much attention because of their use as optical amplifiers, which have been used in the detection of infrared radiation by converting the invisible light into the visible range where conventional detectors are effective also in optical storage, printing, display technology and medicine using up-conversion emission at $550 \mathrm{~nm} .^{3,4)}$ Furthermore, barium titanate $\left(\mathrm{BaTiO}_{3}\right)$ is a very useful host matrix for some applications because it does not absorb energy, allowing it to serve only for support of rare earth ions, which is very useful for these particular applications. ${ }^{5-7)}$ In particular, rare earth (RE) doped NIR-to-visible ceramic oxides represent an alternative and excellent substitute for traditional fluorescent applications. On the other hand, the sol-gel processing is a relatively easy and economical way for making uniform large sized, high quality stoichiometric thin film phosphors, which are especially useful for optical applications. ${ }^{8,9)}$ A new sol-gel process using a high-concentration of alkoxide precursor solutions has proven to have a significant advantage in synthesizing thick-filmed ceramic materials. ${ }^{10,11)}$ By means of this method, transparent, crack-free $\mathrm{BaTiO}_{3}$ monolithic gels and thin films have been successfully synthesized. ${ }^{12,13)}$ However, the thickness of the films remains below $500 \mathrm{~nm}$,

*Corresponding author, E-mail: mgarciah@correo.cua.uam.mx and it is accepted that it is important to obtain a higher thickness in order to fulfill an optical quality for luminescent devices, ${ }^{14)}$ so, it is of high technological importance to increase this parameter. A possible alternative to producing high quality and of $\mathrm{BaTiO}_{3}: \mathrm{Er}^{3+}$ films is to incorporate PVP (polyvinylpirrolidone: as rheological agent $\mathrm{FW}$ : 360000) during the sol-gel synthesis process. ${ }^{15,16)}$ However, its effect in the morphological and luminescent properties is unclear; therefore, the present work studies, by means of three different experimental procedures, the effect of molar ratio and PVP on morphology and photoluminescent properties of Er-doped $\mathrm{BaTiO}_{3}$ sol gel thin films.

\section{Experimental Procedure}

Experimental strategies for the elaboration of Er doped $\mathrm{BaTiO}_{3}$ precursor solutions were carried out by means of three different procedures. The precursors employed were: barium acetate (Aldrich $99.999 \%\left(\mathrm{Ba}\left(\mathrm{CH}_{3} \mathrm{COO}\right)_{2}\right)$ ), titanium isopropoxide (Aldrich $\geq 97 \%$, $\left(\mathrm{Ti}\left[\mathrm{OCH}\left(\mathrm{CH}_{3}\right)_{2}\right]_{4}\right)$ ), titanium butoxide (Fluka $\geq 97 \%\left(\mathrm{TiO}\left[\mathrm{O}\left(\mathrm{CH}_{2}\right)_{3} \mathrm{CH}_{3}\right]_{4}\right)$ ), as source of barium and titanium respectively. Acetic acid (Aldrich, $\geq 99 \%\left(\mathrm{CH}_{3} \mathrm{COOH}\right)$ ) and acetylacetone (Aldrich, $\geq 99 \%$ $\left.\left(\mathrm{CH}_{3} \mathrm{COCH}_{2} \mathrm{COCH}_{3}\right)\right)$ were used as chelating agents with distilled water in order to promote hydrolysis, and Erbium nitrate (Alfa Aesar, 99.9\% $\left(\operatorname{Er}\left(\mathrm{NO}_{3}\right)_{3} \cdot 5 \mathrm{H}_{2} \mathrm{O}\right)$ ) was used as dopant. The molar ratios and special conditions for each type of synthesis (A, B and C) are presented in Table 1. The studied molar relationships correspond to the final results in which a stable sol was formed with varying different synthesis conditions. Synthesis A corresponds to a sol without water, synthesis $\mathrm{B}$ has an acetic acid excess, and synthesis $\mathrm{C}$ is a modification of the reported procedure ${ }^{17)}$ without the use of a different solvent (isopropanol) and 
Table 1 Molar ratio and name label used for the elaboration of Er:BaTiO ${ }_{3}$ films from different methodologies.

\begin{tabular}{|c|c|c|c|c|c|}
\hline \multicolumn{2}{|c|}{ Synthesis Procedure A } & \multicolumn{2}{|c|}{ Synthesis Procedure B } & \multicolumn{2}{|c|}{ Synthesis Procedure C } \\
\hline Precursor & Molar Ratio & Precursor & Molar Ratio & Precursor & Molar Ratio \\
\hline $\mathrm{Ba}(\mathrm{OAc})_{2}$ & $1-\mathrm{x}$ & $\mathrm{Ba}(\mathrm{OAc})_{2}$ & $1-x$ & $\mathrm{Ba}(\mathrm{OAc})_{2}$ & $1-\mathrm{x}$ \\
\hline $\mathrm{AcOH}$ & 52 & $\mathrm{AcOH}$ & 18 & $\mathrm{AcOH}$ & 7 \\
\hline $\mathrm{Ti}(\mathrm{OBu})_{4}$ & 1 & $\mathrm{Ti}(\mathrm{OBu})_{4}$ & 1 & TPOT & 1 \\
\hline $\operatorname{ACAC}(\mathrm{H})$ & 4 & $\operatorname{ACAC}(\mathrm{H})$ & 1 & $\mathrm{ACAC}(\mathrm{H})$ & 9.2 \\
\hline Water & - & Water & 40 & Water & 40 \\
\hline PVP & 1 & PVP & 1 & PVP & 1 \\
\hline
\end{tabular}

Abbreviations: $\mathrm{Ba}(\mathrm{OAc})_{2}$ : Barium acetate; $\mathrm{Er}\left(\mathrm{NO}_{3}\right)_{3}{ }^{*} 5 \mathrm{H}_{2} \mathrm{O}$ : Erbium nitrate pentahydrate; AcOH: Acetic acid; Ti(OBu $)_{4}$ : titanium butoxide; TPOT: titanium isopropoxide; $\mathrm{ACAC}(\mathrm{H})$ : acetylacetonate; PVP: polyvinylpirrolidone.

stabilized with the minimum acetic acid content, since an excess of this promotes the formation of cracks and promotes the growth of grain size. ${ }^{18)}$ In the present work, the concentration of barium in solution was $1 \mathrm{~mol} \mathrm{~L}^{-1}$ and the doping concentration was fixed at $5 \mathrm{~mol} \%$. PVP was incorporated in all solutions at a $1: 1$ molar ratio with respect to barium.

Erbium doped $\mathrm{BaTiO}_{3}$ films were obtained from the precursor solutions sols using a dip-coating technique onto fine polished optical silica substrates. In order to obtain optical quality of the films, the substrate were carefully washed using a special protocol. ${ }^{19)}$ The substrates were dipcoated using a withdrawal speed of $0.25 \mathrm{~cm} \mathrm{~min}^{-1}$ for all cases. Only a single layer was deposited on the substrate and thermally annealed from room temperature to $700^{\circ} \mathrm{C}$ at $0.5^{\circ} \mathrm{C} \mathrm{min}^{-1}$ at $5 \mathrm{~min}$ at the final temperature.

\subsection{Characterizations}

Crystal structure was determined by X-ray diffractometry (D8 Advance, Bruker AXS) using a $\mathrm{Cu}-\mathrm{K} \alpha$ monochromatized radiation at $35 \mathrm{kV}, 25 \mathrm{~mA}$ over the $2 \mathrm{~h}$ range $25-90^{\circ}$ $\left(0.1^{\circ} / \mathrm{s}\right)$, set on powder configuration. Surface morphology was evaluated by field emission scanning electron microscopy (FE-SEM, HITACHI, S5000) and atomic force microscopy with a Nanoscope IV apparatus (Digital Instruments) in tapping mode. Luminescence spectra were obtained by pumping samples with a Spectra Physics Quanta-Ray Nd:YAG-MOPO tunable laser system, and luminescence was collected at a right angle by an optical system and dispersed by an Acton Research SpectraPro 500i spectrometer with Hamamatsu PMT detector, R326 for NIR regions. In order to analyze the optical quality of the prepared films, as well as the thickness, refractive index, density and porosity, m-lines spectroscopy was carried out with a $\mathrm{He}-$ Ne laser $(543.5 \mathrm{~nm})$ coupled with a LaSF 35 angle $60^{\circ}$ prism.

\section{Results and Discussion}

XRD profiles of $\mathrm{Er}^{3+}(5 \mathrm{~mol} \%)$ doped $\mathrm{BaTiO}_{3}$ monolayer film for each synthesis procedure are shown in Fig. 1. No secondary phases are found within the detection limit of $\mathrm{XRD}$. The results revealed that the dried gel films crystallized after $700^{\circ} \mathrm{C}$ heat treatment. However, at this temperature Figs. 1(a) and 1(b) shows an amorphous zone in the range of $2 \theta=20-30^{\circ}$, which could be associated with an excess

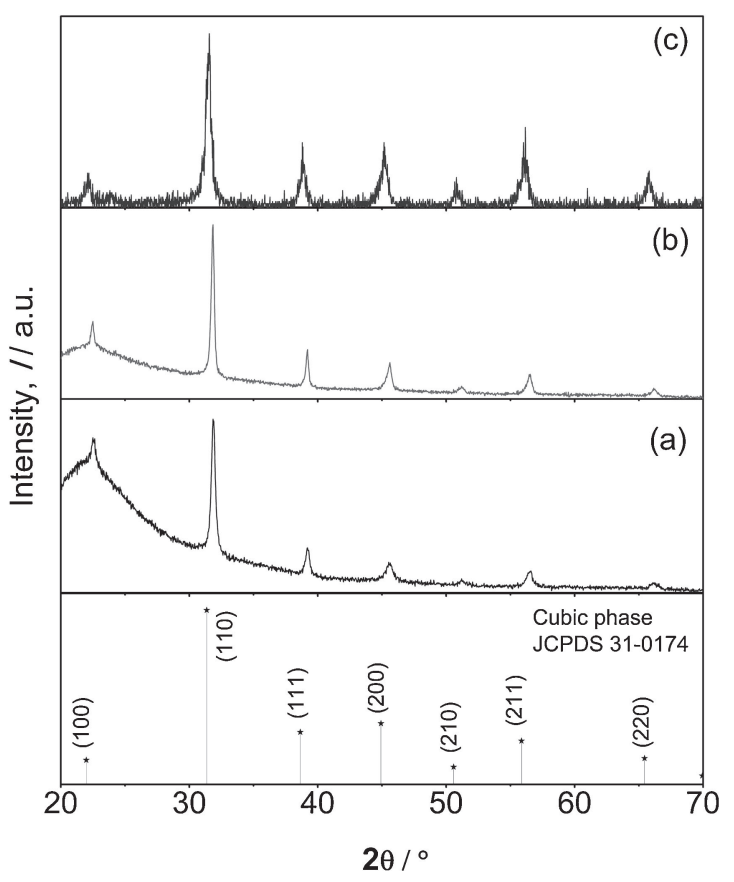

Fig. 1 X-ray diffraction pattern of Er:BaTiO ${ }_{3}$ films obtained from synthesis $\mathrm{A}(\mathrm{a}), \mathrm{B}(\mathrm{b})$ and $\mathrm{C}$ (c) methodologies annealing to $700^{\circ} \mathrm{C}$.

of acetic acid present during the formation of the sol. Figure 1(c) corresponds with the film obtained from $\mathrm{C}$ methodology; in this X-ray pattern, the complete crystallization in the pseudocubic phase is present in accord with the JCPDS 31-0174 card. As observed, the PVP does not affect the normal crystallization of $\mathrm{BaTiO}_{3}$. The crystallite size shown in the same Fig. 1, ranges from 13 to $20 \mathrm{~nm}$. The different synthesis procedures do not greatly affect the crystal structure of the films, nor the crystallite size; therefore, the differences in the luminescent properties can be attributed to the morphology and thickness of the films.

Figure 2 shows an image of the synthesized films that go along with procedures $\mathrm{A}, \mathrm{B}$ and $\mathrm{C}$ respectively. As can be observed, only the $\mathrm{C}$ synthesis produces transparent films, whereas procedures $\mathrm{A}$ and $\mathrm{B}$ produce opaque films. The surface morphology of the $\mathrm{Er}^{3+}: \mathrm{BaTiO}_{3}$ films prepared under $\mathrm{A}, \mathrm{B}$ and $\mathrm{C}$ methodologies using PVP via single-step dipcoating is illustrated in Figs. 3(a)-3(c). The top view of the micrograph for $\mathrm{Er}^{3+}: \mathrm{BaTiO}_{3}$ prepared from methodology A (Fig. 3(a)) (without water) showed a heterogeneous surface 
due to the decomposition of gaseous species in a violent form during the sol evaporation, which causes the formation of large pores. Furthermore, as observed, several cracks have been formed. The micrograph of the $\mathrm{Er}^{3+}: \mathrm{BaTiO}_{3}$ film

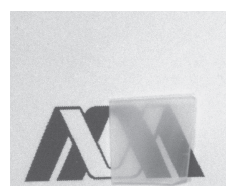

(a)

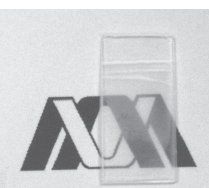

(b)

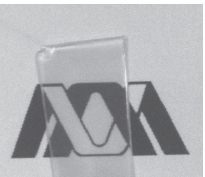

(c)

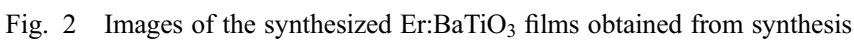
$\mathrm{A}(\mathrm{a}), \mathrm{B}(\mathrm{b})$ and $\mathrm{C}$ (c) methodologies annealing to $700^{\circ} \mathrm{C}$. prepared under B methodology (Fig. 3(b)) present a uniform cross-linked surface, and it is clear that the films present a more homogenous structure as compared with synthesis A. However, for the film prepared under methodology $\mathrm{C}$ (Fig. 3(c)), the morphology of the film is considerably different. In this case, the molar ratio of acetic acid/Ba (7:1) and water in excess promotes significant differences in the morphological observations, since the surface presents a flowerlike shape composed of an agglomeration of nanocrystallites, and the same aspect of this morphology was observed in a previous work ${ }^{20)}$ in which isopropanol was used as a solvent. Some reports describe this behavior due to the crystal twinning at the onset of growth, their shape and size related with the molar ratio of the starting materials. ${ }^{21,22)}$
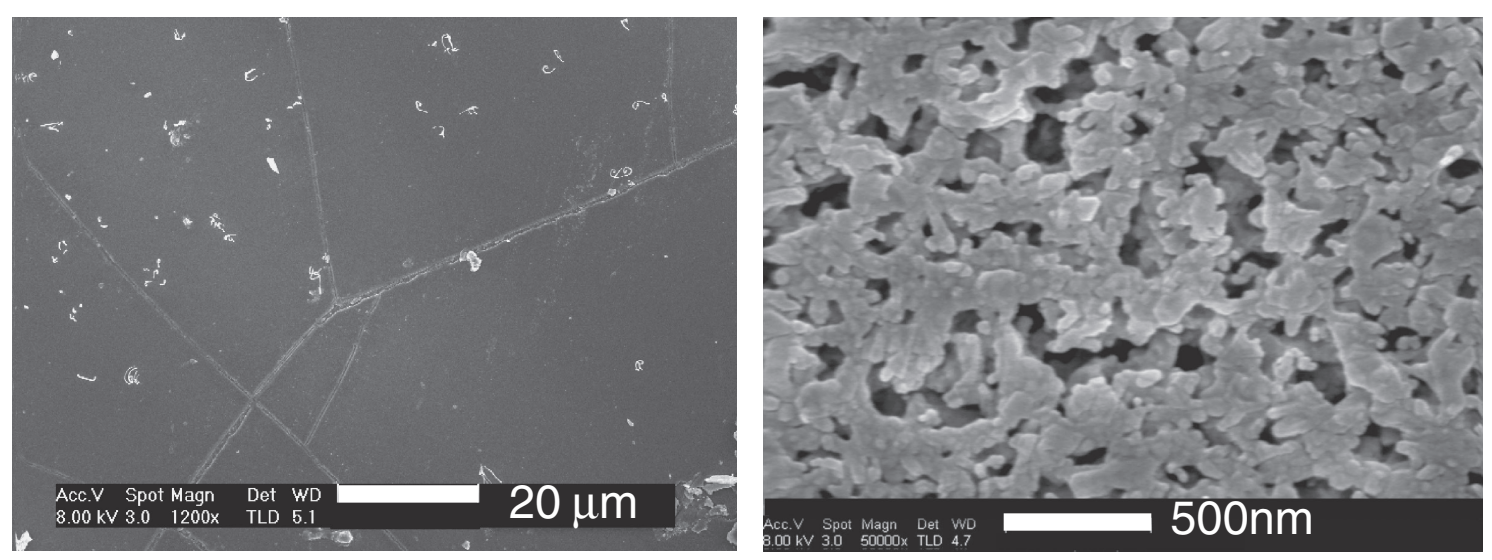

(a)
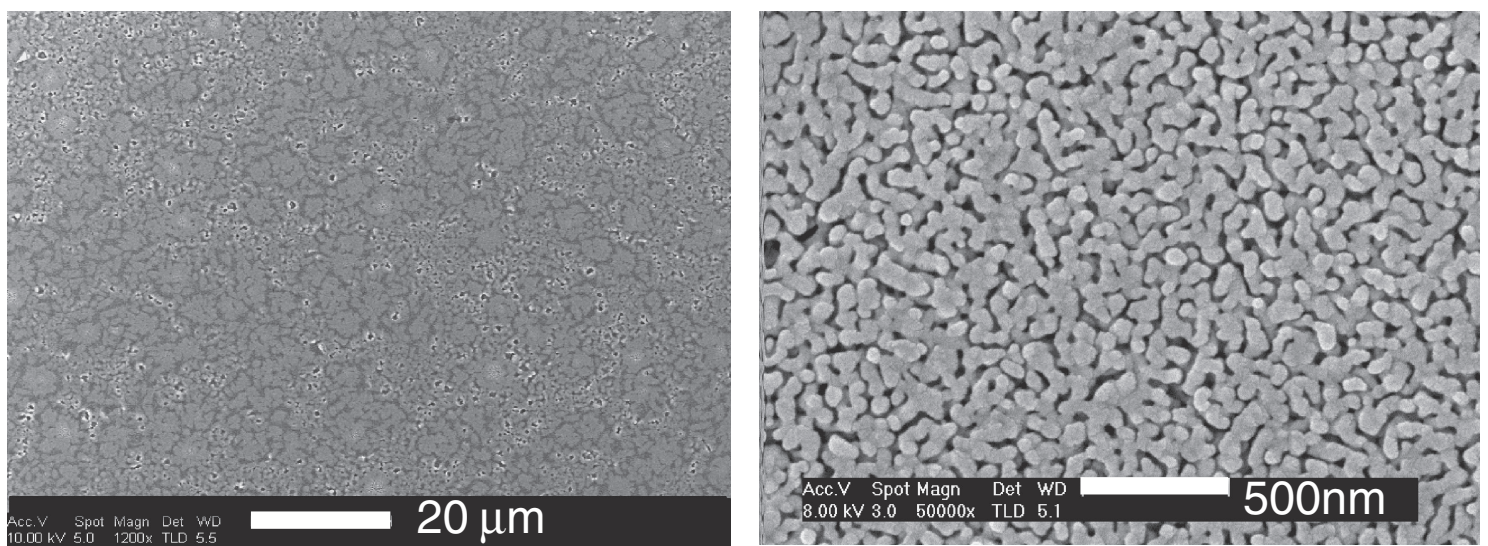

(b)
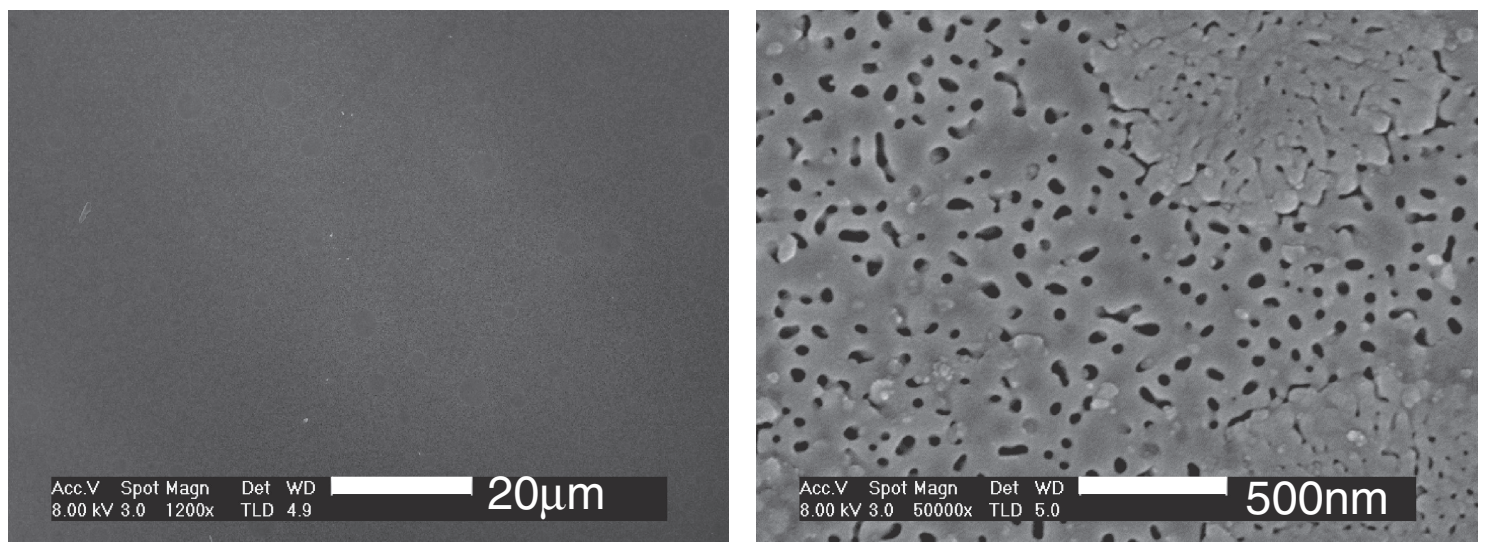

(c)

Fig. 3 SEM micrographs at two different magnification: $1200 \times$ (left) and $50000 \times\left(\right.$ right) of Er-doped $\mathrm{BaTiO}_{3}$ films from synthesis A (a), $\mathrm{B}(\mathrm{b})$ and $\mathrm{C}(\mathrm{c})$ annealing at $700^{\circ} \mathrm{C}$. 


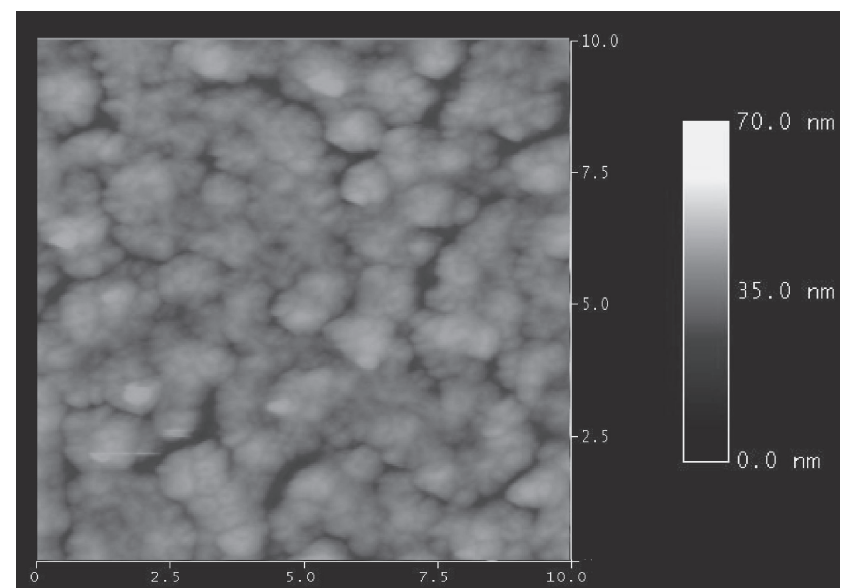

(a)

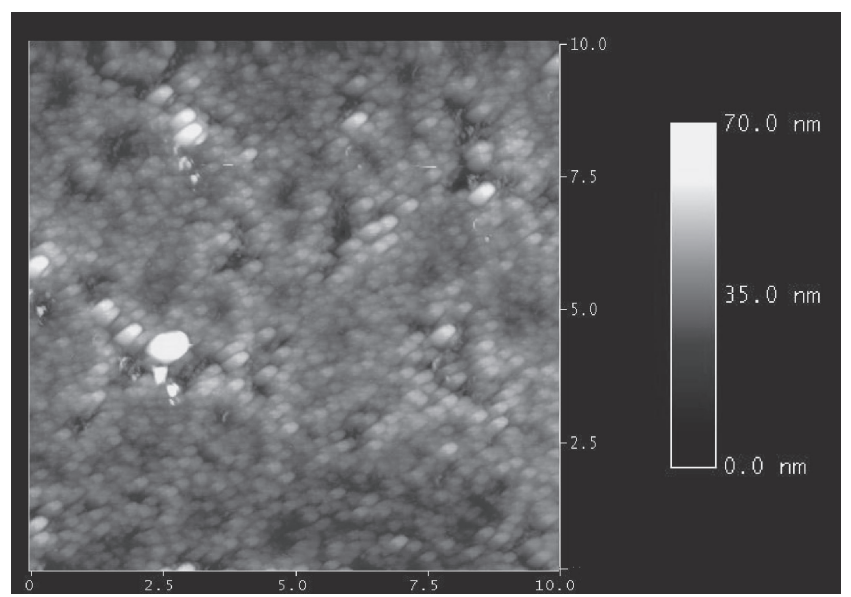

(b)

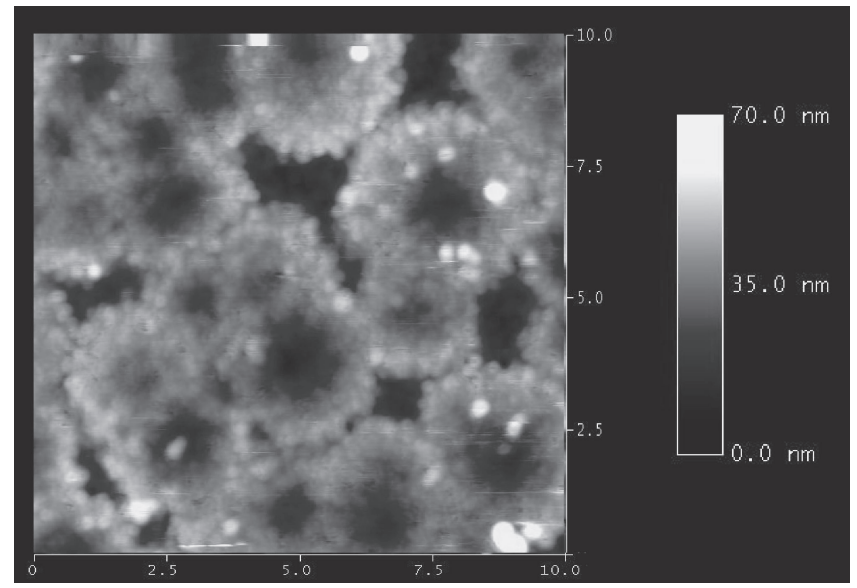

(c)

Fig. 4 Typical AFM micrographs showing the surface of Er-doped $\mathrm{BaTiO}_{3}$ films from synthesis A (a), B (b) and C (c) annealing at $700^{\circ} \mathrm{C}$.

Figures 3(b) and 3(c) exhibit optical qualities on the surface, attributed to strong hydrogen bonding interactions between $\mathrm{C}=\mathrm{O}$ groups from $\mathrm{PVP}$, acetic acid and the $\mathrm{OH}$ groups of the metalloxane $\mathrm{Ti}-\mathrm{O}$ polymers from $\mathrm{BaTiO}_{3}$. Such $\mathrm{C}=\mathrm{O}$ groups can be regarded as the capping agent for the $\mathrm{OH}$ groups of the metalloxane polymers; they suppress the condensation reaction and promote structural relaxation. ${ }^{20)}$ Figures 4(a)4(c) shows the surface images characterized by the AFM analysis. Its mean square roughness (RMS) was estimated at 15,5 and $13 \mathrm{~nm}$ for $\mathrm{A}, \mathrm{B}$ and $\mathrm{C}$ films respectively,

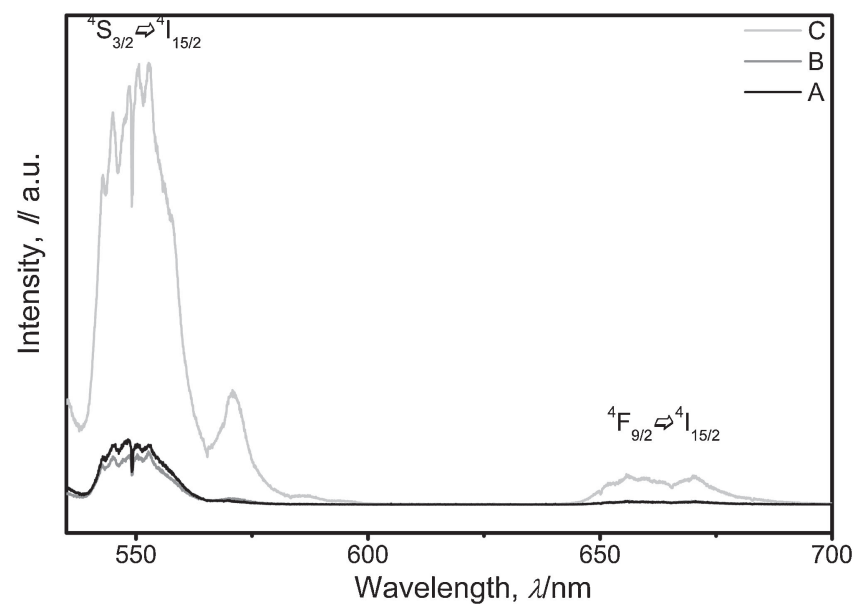

Fig. 5 Emission spectra of $\mathrm{Er}_{\mathrm{BaTiO}}$ after $\lambda=974 \mathrm{~nm}$ excitation.

which demonstrates that the PVP addition doesn't affect the smoothness of the produced films. Agglomeration particles with pores, homogeneous surface and flowerlike particles were observed in accord with MEB observations. Based on these results, it could be concluded that the final optical properties of the films have to be tailored by their microstructure.

$\mathrm{m}$-Lines spectroscopy is a useful method to determine the optogeometric parameters of waveguiding thin films, such as refractive index as well as film thickness. In optical films, light propagation occurs within a transparent material when the film has sufficient thickness to support at least one guided mode: either a transverse electric mode (TE) or a magnetic mode (TM). Therefore, the optical quality of a film can be associated if it can support this propagation. In the present work, only the synthesis $\mathrm{C}$ produces a film with the necessary transparency, homogeneity and thickness to be characterized by this technique. The thickness of the film was determined as $720 \mathrm{~nm}$, with a refrax index of 2.1225 . The density of the films can be determined by means of the Lorenz-Lorentz equation and the pore content by Drude's equation. ${ }^{23)}$ The calculated density of the film is $5.17 \mathrm{~g} \mathrm{~cm}^{-3}$ with a pore content of $30.38 \%$. As observed, the obtained density is $85 \%$ of the theoretical $\left(6.02 \mathrm{~g} \mathrm{~cm}^{-3}\right)$, which suggests that the material presents a dense structure. On the other hand, as expected, the pore content is relatively high because the presence of the flower-type microstructure observed by SEM and AFM, which is a product of the preferential nucleation of the ceramic.

The excitation spectra monitoring $548 \mathrm{~nm}$ emission lines of the Er doped $\mathrm{BaTiO}_{3}$ films prepared under $\mathrm{A}, \mathrm{B}$ and $\mathrm{C}$ strategies are presented in Fig. 5. In this emission spectra excited at $\lambda=974 \mathrm{~nm}$, it clearly shows high luminescence efficiency achieved under IR radiation excitation, and the emission is bright even to the naked eye. When pumped at $974 \mathrm{~nm}$ excitation, cooperative energy transfer (CET) also takes place and results in green up-conversion emission. It is known that ${ }^{4} \mathrm{I}_{11 / 2}$ has zero emission probability to the ground state. ${ }^{24)}$ The main shoulder around $550 \mathrm{~nm}$ is more intense for the film prepared under $\mathrm{C}$ sol preparing conditions than those observed on films prepared for A and B conditions where an excess of acetic acid is present in the sol elaboration step. 
In all cases, the whole profile of emission peak seems to remain unchanged, similar to the other erbium doped samples. ${ }^{20)}$ These results are in agreement with the morphological observations, since it is well known that the light yield of films are strongly dependent on transparency and homogeneity; therefore, synthesis $\mathrm{C}$, which is the only one that is crack-free, transparent and dense, presents the highest emission. Finally, although the flower-like microstructure of the film could diminish the emission, this microstructure is the product of the PVP agent and the combination of an adequate molar relationship of acetic acid and acetylacetonate. The PVP is aggregated in order to increment the thickness of the films, since for monolayer films; the typical thickness obtained by sol-gel is $120 \mathrm{~nm}^{25)}$

\section{Conclusion}

Er:BaTiO ${ }_{3}$ films were elaborated from different molar ratios of starting materials synthesized through methodologies A, B and C. X-ray diffraction, scanning electron and atomic force microscopes were utilized to investigate the effect of the starting molar ratios on the microstructure's characteristics. High contents of acetic acid bring on homogeneous and cross-linked particles on the surface films. Using a moderate quantity of acetic acid and an excess of distilled water, the morphology on the surface films changed considerably, forming an agglomeration of particles in flower shapes (methodology C). The $\mathrm{Er}_{\mathrm{BaTiO}}$ films prepared under methodology $\mathrm{C}$ presented better emission lines in $548 \mathrm{~nm}$ when excited at $\lambda=974 \mathrm{~nm}$. We may expect that the Erbium ions doped $\mathrm{BaTiO}_{3}$ films are a possible candidate for optical application.

\section{Acknowledgments}

The authors gratefully acknowledge the financial support of SEP-CONACYT (100764, $136269 \& 178817)$ projects.

\section{REFERENCES}

1) V. Nazabal, S. Todoroki, S. Inoue, T. Matsumoto, S. Suehara, T.
Hondo, T. Araki and T. Cardinal: J. Non-Cryst. Solids 326-327 (2003) 359-363.

2) F. Wang and X. G. Liu: Chem. Soc. Rev. 38 (2009) 976-989.

3) H. X. Zhang, C. H. Kam, Y. Zhou, X. Q. Han, S. Buddhudu and Y. L. Lam: Opt. Mater. 15 (2000) 47-50.

4) G. Schlaghecken, J. Gottmann, E. W. Kreutz and R. Poprawe: Appl. Phys. A 79 (2004) 1255-1257.

5) Y. Umeda, K. Masuzawa, S. Ueda, S. Ootsuki, A. Kuwabara and H. Moriwake: Ceram. Int. 38 (2012) S25-S28.

6) W. Strek, D. Hreniak, G. Boulon, Y. Guyot and R. Pązik: Opt. Mater. 24 (2003) 15-22.

7) A. García Murillo, F. J. Carrillo Romo, M. García Hernández, O. Barbosa García, A. Meneses Nava, S. Palomares Sánchez and A. Flores Vela: Mater. Trans. 50 (2009) 1850-1854.

8) A. de J. Morales Ramírez, A. García Murillo, F. de J. Carrillo Romo, M. García Hernández, E. de la Rosa and J. Moreno Palmerin: J. SolGel Sci. Technol. 58 (2011) 366-373.

9) A. García Murillo, F. de J. Carrillo Romo, C. Le Luyer, A. de J. Morales Ramírez, M. García Hernández and J. Moreno Palmerin: J. Sol-Gel Sci. Technol. 50 (2009) 359-367.

10) T. Nishide and M. Shibata: J. Sol-Gel Sci. Technol. 21 (2001) 189-193.

11) J. Li and M. Kuwabara: Sci. Technol. Adv. Mat. 4 (2003) 143-148.

12) M. H. Frey and D. A. Payne: Chem. Mater. 7 (1995) 123-129.

13) M. García-Hernández, A. García-Murillo, F. de J. Carrillo-Romo, D. Jaramillo-Vigueras, G. Chadeyron, E. De la Rosa and D. Boyer: Int. J. Mol. Sci. 10 (2009) 4088-4101.

14) W. C. Chien: J. Cryst. Growth 290 (2006) 554-559.

15) H. Kozuka: J. Sol-Gel Sci. Technol. 40 (2006) 287-297.

16) H. Kozuka, M. Kajimura, T. Hirano and K. Katayama: J. Sol-Gel Sci. Technol. 19 (2000) 205-209.

17) A. García Murillo, F. J. Carrillo Romo, M. García Hernández, J. Ramírez Salgado, M. A. Domínguez Crespo, S. A. Palomares Sánchez and H. Terrones: J. Sol-Gel Sci. Technol. 53 (2010) 121-133.

18) B. C. Jiao, X. D. Zhang, C. C. Wei, J. Sun, Q. Huang and Y. Zhao: Thin Solid Films 520 (2011) 1323-1329.

19) M. Bahtat, J. Mugnier, L. Lou, C. Bovier, J. Seruguetti and M. Genet: J. Opt. 23 (1992) 215-222.

20) M. García Hernández, F. de J. Carrillo Romo, A. García Murillo, D. Jaramillo Vigueras, M. A. Meneses Nava, P. Bartolo Pérez and G. Chadeyron: J. Sol-Gel Sci. Technol. 53 (2010) 246-254.

21) H. Kozuka, M. Kajimura, K. Katayama, Y. Isota and T. Hirano: Mater. Res. Soc. Symp. Proc. 606 (1999) 187-192.

22) J. Xu, J. Zhai, X. Yao, J. Xue and Z. Huang: J. Sol-Gel Sci. Technol. 42 (2007) 209-212.

23) P. K. Tien and R. Ulrich: J. Opt. Soc. Am. 60 (1970) 1325-1337.

24) Y. Chen, Y. Huang, M. Huang, R. Chen and Z. Luo: Opt. Mater. 25 (2004) 271-278.

25) R. N. Gayen, K. SarKar, S. Hussain, R. Bhar and A. K. Pal: Ind. J. Pure Appl. Phys. 49 (2011) 470-477. 